\title{
Seismic risk assessment of the rural road network
}

\author{
S. Cafiso, A. L. Bruna \& G. L. Cava \\ Department of Civil and Environmental Engineering, \\ University of Catania, Italy
}

\begin{abstract}
In the case of damage produced by seismic events the effects of an interruption to the road network and the consequent reduction of what remains available greatly affect the overall performance of the system.

Thus, the need to guarantee that the transport network functions after seismic events requires a seismic risk analysis of the road system which is able to evaluate the effects of earthquakes beforehand in order to define a priority ranking for maintenance and seismic retrofit programs.

This paper proposes a methodology for the evaluation of seismic risk on rural road networks. The model used to define the risk level of the road lifelines is based on the product of three factors: area seismic hazard, road link seismic exposure, bridge seismic vulnerability.

A network risk analysis was carried out to measure network performance as related to its capability to oppose or react against the failure of one or more elements. The methodology has been designed for use with the Geographic Information System (GIS). A case study carried out in a GIS environment, showed the potential of the model to highlight which towns and links are in the most critical condition.
\end{abstract}

Keywords: road network, lifeline, seismic risk, GIS, bridge, exposure, vulnerability, hazard, damage.

\section{Introduction}

In the case of damage produced by seismic events, the effects of an interruption to the road network and the consequent reduction of what remains available profoundly affect the overall performance of the system (increasing traveling 
time, distance and costs). What is more, if emergency services are to reach the affected area quickly the road network must be reliable, that is, it must ".... provide a safe and not fluctuating service for the traffic and offer the users alternative routes, even when some parts of the system are not available due to road accidents, maintenance or natural disasters" (Wakabayashi and Idia [1]).

Parallel to the concept of reliability it is indispensable that problems linked to the network risk are addressed (Cafiso et al. [2,3]).

On the basis of experience acquired with road network damage after a strong earthquake, all analyses were conducted considering bridges to be the weak road element when an earthquake strikes. This research, with reference to different seismic emergency scenarios, presents a method for evaluating beforehand the level of risk that emergency service routes along the road network will be interrupted due to bridges being damaged.

Its geographical position and the presence of the active volcano, Mount Etna, make eastern Sicily a region at high seismic risk. For this reason, the area was chosen as a case study. The paper presents an example applied to a limited area but which is nevertheless useful for the application of the risk model.

\section{Risk analysis}

Risk analysis of road network can be carried out, following an approach that has been well consolidated in literature (Cafiso et al. [4]), as the product of three independent factors:

A) Hazard, linked to the probability that in a certain place there will be an event of a certain intensity with a given return time;

B) Vulnerability, which defines the propensity of an infrastructural element to undergo damage during the event;

C) Exposure, given by the number of people (and goods) that can be damaged by the event.

\subsection{Vulnerability}

Vulnerability is defined as the measurement of the propensity for efficiency to be lost in the carrying out of those functions that normally work correctly. To evaluate the seismic vulnerability of the bridges forming part of a road network, reference was made to a published model (Buckle and Kim [5]), which is particularly effective for the proposed approach:

- it minimizes the arbitrariness of subjective judgement;

- all the parameters indicated by the procedure can be directly applied to bridges in the area under investigation;

- the way of determining damage as a product of hazard and vulnerability is suitable for the risk evaluation method adopted;

- the model provides a numerical damage index.

In the model, the level of vulnerability is obtained using a linear regression of the damage indicators recorded during seismic events and related to evaluation parameters present in the model: 


$$
\mathrm{V}=\sum_{\mathrm{i}} \beta_{\mathrm{i}} \times \mathrm{X}_{\mathrm{i}}
$$

where: $X_{i}$ is the value assumed by the model evaluation parameters (Intensity of Peak Ground Acceleration, Design Specification, Type of Superstructure, Shape of Superstructure, Internal Hinge, Type of Pier, Type of Foundation, Material of Substructure, Irregularity in Geometry or in Stiffness, Site Condition, Effect of Liquefaction, Seat Length);

$\beta_{\mathrm{i}}$ is the weighting factors for each attribute;

This index represents, therefore, the vulnerability level of the structure.

\subsection{Hazard}

The seismic hazard is the degree of probability that a damaging seismic event will take place in a given area in a particular time period. Peak Ground Acceleration (PGA) was used as the seismic danger measurement parameter. This parameter can be obtained from the seismic maps produced by the National Institute of Geophysics and Volcanology (I.N.G.V.) [6] in terms of $\mathrm{a}_{\mathrm{g}}$ (maximum soil acceleration) with an $81 \%, 63 \%, 50 \%, 39 \%, 22 \%, 10 \%, 5 \%, 2 \%$ probability of exceeding this in 50 years, corresponding to a return time period of $30,50,72$, $100,200,475,975$ and 2475 years.

Based on the chronological history of seismic events in the investigated area, three levels of severity were chosen, characterised by different return times:

1) events having a return time period of 50 years for the most frequent shakes.

2) events having a return time period of about 100 years for not particularly severe and localised earthquakes.

3 ) events having a return time period of 475 years which corresponds to the strongest seismic events taken into consideration by building regulations.

Using specific GIS tools, it was first of all possible to perform the passage from the PGA grid point values supplied by the I.N.G.V. [6] to area values and then, using an "overlay analysis" procedure, it was possible to attribute a specific PGA value to each bridge previously localized in the area (Figure 1).

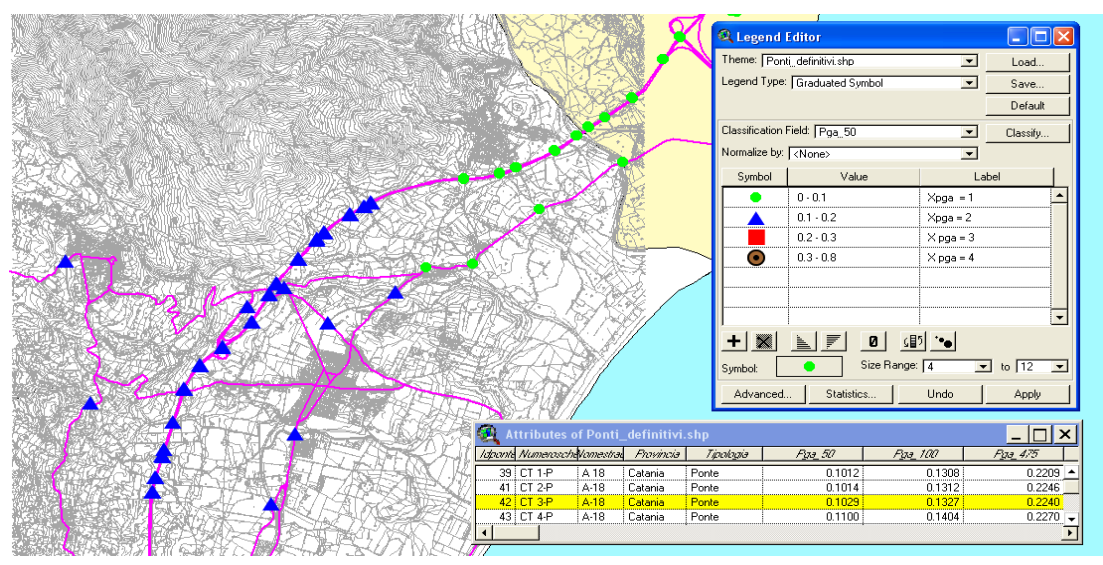

Figure 1: $\quad 50,100$ and 475-year PGA maps of bridges on the road network. 


\subsection{Damage}

Once the vulnerability (V) was defined and the Hazard noted, the adopted model made it possible to obtain the expected damage index for each bridge by means of the following relation:

$$
\mathrm{D}=\mathrm{X}_{\mathrm{PGA}} \times \mathrm{V}
$$

where $\mathrm{X}_{\mathrm{PGA}}$ is the hazard index assuming the values shown in Table 1 .

Table 1: $\quad$ Hazard index $\mathrm{X}_{\mathrm{PGA}}$.

\begin{tabular}{|l|l|l|l|}
\hline PGA & $\mathbf{X}_{\mathbf{P G A}}$ & $\mathbf{P G A}$ & $\mathbf{X}_{\mathbf{P G A}}$ \\
\hline $\mathrm{PGA}<0,1 \mathrm{~g}$ & 1 & $0,2 \mathrm{~g} \leq \mathrm{PGA}<0,3 \mathrm{~g}$ & 3 \\
\hline $0,1 \mathrm{~g} \leq \mathrm{PGA}<0,2 \mathrm{~g}$ & 2 & $\mathrm{PGA} \geq 0,3 \mathrm{~g}$ & 4 \\
\hline
\end{tabular}

The damage D can assume values of between 0 and 9 to which 4 different $\operatorname{Tr}$ index values have been associated according to the transitability of the stretch of road (Table 2).

Table 2: $\quad$ Damage values D and transitability index Tr.

\begin{tabular}{|l|l|l|}
\hline $\begin{array}{l}\text { Damage } \\
\text { D }\end{array}$ & Transitability & $\mathbf{T r}$ \\
\hline $\mathrm{D}=0$ & No damage (completely transitable) & 0 \\
\hline $0<\mathrm{D}<5$ & Slight damage (transitable with caution) & 1 \\
\hline $5 \leq \mathrm{D}<7$ & Moderate damage (restricted transit) & 5 \\
\hline $7 \leq \mathrm{D}$ & Considerable damage/collapse (no transit) & 10 \\
\hline
\end{tabular}

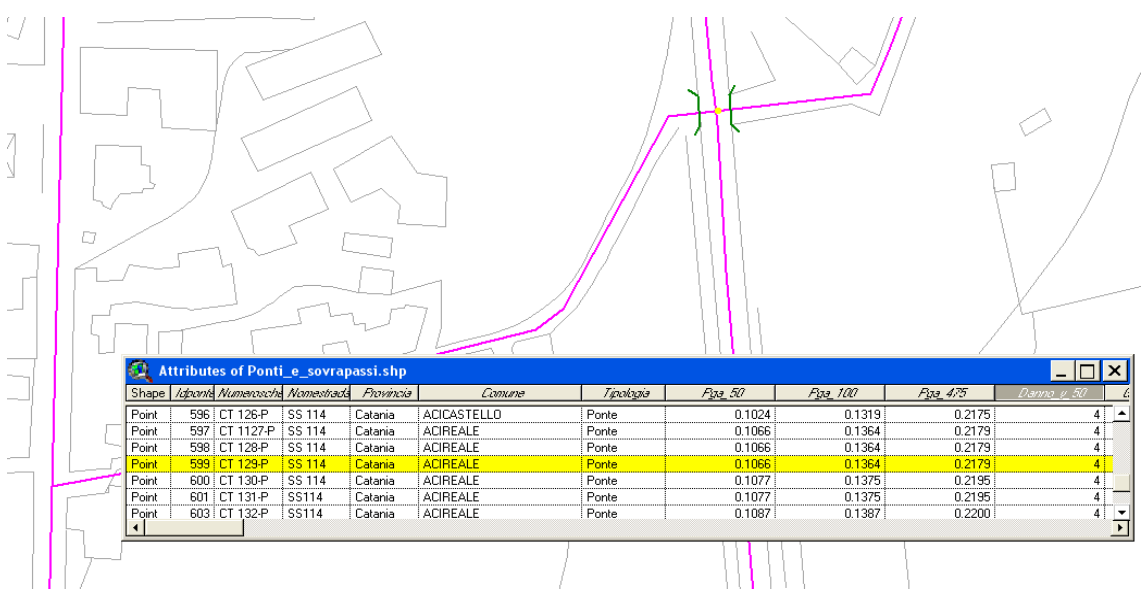

Figure 2: GIS damage and transitability attributes of bridges in the road network. 
Figure 2 shows how a respective damage value D and transitability index $\mathrm{Tr}$ have been attributed to each bridge and overpass according to the differences in the return period taken into consideration $(T=50,100,475$ years $)$

\subsection{Exposure}

Seismic exposure represents the quantity and quality of the various anthropical elements (population, buildings, infrastructure, etc.) whose conditions and running could be damaged by a seismic event. The population is the main category at risk. To each town a "direct exposure" value was assigned equal to the number of its inhabitants multiplied by the 'index of seismic risk' which in Italy is defined proportionally to expected losses and with a value varying between 0 and 0.8 [7].

Moreover, "indirect exposure" on single stretches of the road network can be defined in relation to the number of people who would experience delays in the arrival of emergency services due to an interruption of that given stretch of the network. Defining the route between an origin (O) and a destination (D), to each of the stretches along this route, an "indirect exposure" was assigned equal to the direct exposure value assigned to the town of destination.

\section{Geographical information system}

The province of Catania has an area of about $3,552 \mathrm{Km}^{2}$ with a population of $1,054,778$ inhabitants, in which there are 58 towns/cities.

The GIS, developed using Arcview ${ }^{\circledR}$, contains all the data necessary for an analysis of risk and emergency management, organized in shape-files and relational databases. All the bridges and overpasses present on the road network were positioned within the GIS with the help of 1:10,000 scale maps of the province. 321 bridges and overpasses situated on stretches of the road network within the study zone were loaded into the GIS.

The shape-file relating to the roads present in the province of Catania and the segmentation of the network as connected links make it possible to use the Network Analyst ${ }^{\circledR}$ function to define routes from Origin $(\mathrm{O})$ to Destination (D).

In particular, two emergency service origins were chosen:

1) Origin North $(\mathrm{N})$ : the motorway interchange in Giardini Naxos, which is the starting point for emergency services coming from the northern part of the province of Catania;

2) Origin West (W): the interchange in San Gregorio on the Catania urban Freeway, relating to emergency services coming from eastern Sicily and the southern part of the province of Catania.

As regards destinations, five towns in the study zone, with populations of more than 2,000 inhabitants, were considered:

Acireale (33,010 inhabitants), Santa Venerina (4,056 inhabitants), Aciplatani (3,269 inhabitants), Linera (2,781 inhabitants), Guardia Mangano (2,457 inhabitants). 


\section{Risk evaluation}

The risk factor calculated is associated to the emergency services' access to the towns in the case of earthquake. Therefore, the road network risk analysis was defined by associating the Damage (Hazard x Vulnerability) and Exposure factors to both the network roads and connected towns.

The procedure comprises the following five phases:

1) assignment of a damage and transitability index to links of the network roads;

2) establishment of the $\mathrm{O} / \mathrm{D}$ routes on the road network;

3) assignment of an indirect exposure factor to the roads along the routes;

4) risk evaluation of the links forming the road network;

5) risk evaluation of the town.

\subsection{Phase 1 - assignment of damage and transitability index}

Various basic attributes are assigned to each stretch of the network in the GIS among which journey Length and Time. The Damage and Transitability indexes were added to these attributes. When dealing with stretches where there are no bridges or overpasses then both Damage and Transitability were taken as being equal to 0 for any earthquake scenario (50, 100 and 475 years). For those stretches where there is one bridge or overpass the Damage and Transitability indexes were assigned on the basis of values taken from the previouslyillustrated model for the various earthquake scenarios at 50, 100 and 475 years (Table 2). Finally, if there is more than one bridge and/or overpass then the Damage and Transitability indexes of the stretch were considered as being equal to the maximum of the values attributed to the different bridges or overpasses.

\subsection{Phase $2-O / D$ routes}

After having defined the two origins (O) and the five destinations (D) in the earthquake scenario, eight different routes were identified for each $\mathrm{O} / \mathrm{D}$ connection which minimized respectively Length, Time, Damage and Transitability attributes at 50, 100 and 475 years which had previously been assigned to the stretches of the road network.

\subsection{Phase 3 - indirect exposure factor}

An indirect exposure value was assigned to each stretch of the road network constituting part of the O/D route equal to the number of inhabitants in the town of destination multiplied by its seismic risk index (direct exposure of the town).

Once all the eight $\mathrm{O} / \mathrm{D}$ routes of the same type had been analysed an indirect exposure value was associated to each stretch of the network equal to the sum of the values attributed to the link in each of the eight $\mathrm{O} / \mathrm{D}$ simulations. Therefore, some stretches of the network have a nil exposure, because they have never been used for $\mathrm{O} / \mathrm{D}$ routes. Others have an exposure value based on a single destination, while those which have been used a number of times in order to reach different destinations have an exposure value equal to the sum of the exposures of the towns for which the stretch is used for that type of route. 


\subsection{Phase 4 - risk evaluation of the links}

When the damage value (Phase 2) and the indirect exposure of each single stretch of the network (Phase 3) are known it is then possible to obtain the risk value relating to that particular type of route, by multiplying the damage value by the exposure value.

$$
\text { Risk }=\text { Indirect exposure } \times \text { Damage }
$$

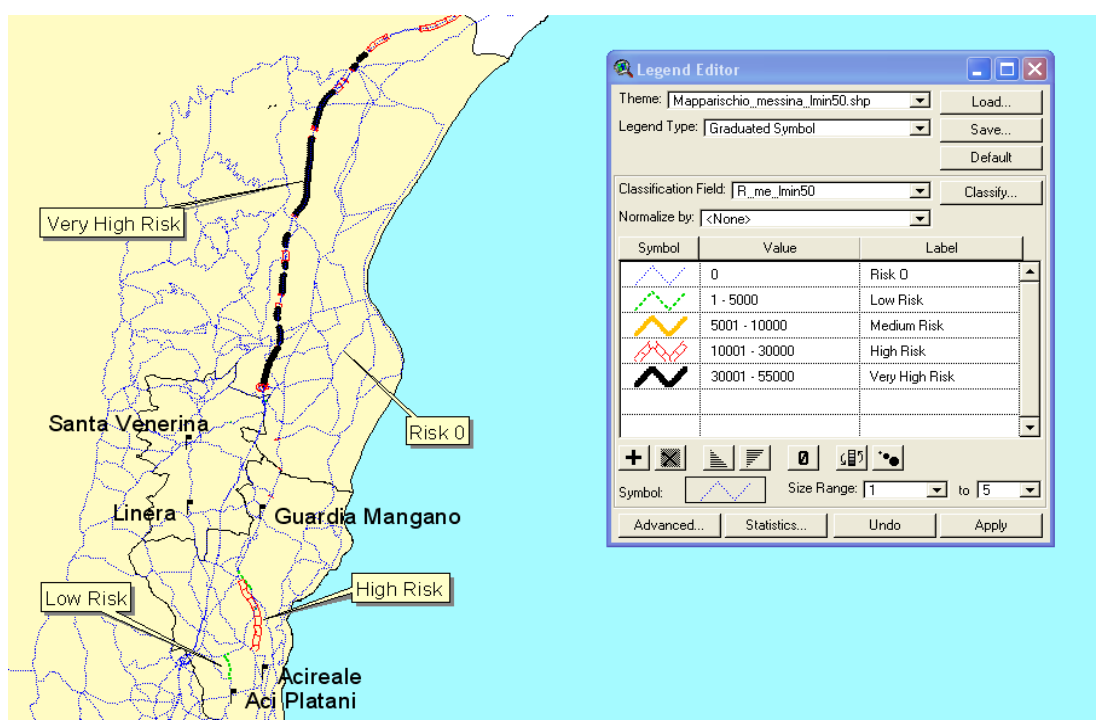

Figure 3: Thematic risk map for the minimum length route.

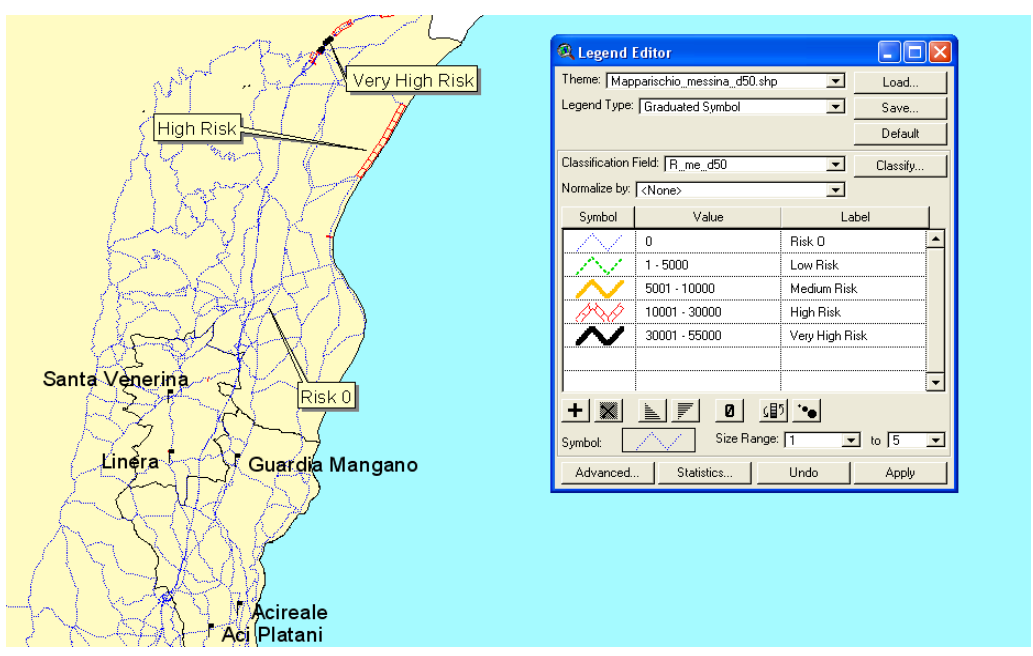

Figure 4: $\quad$ Thematic risk map for the route with minimum damage. 
24 risk maps were drawn up for each of the origins:

- $\quad$ Four Risk maps showing minimum length routes for 50-, 100- and 475-year periods (Figure 3)

- Four Risk maps showing minimum time routes for 50-, 100- and 475-year periods

- Four Risk maps showing minimum damage routes for 50-, 100- and 475year periods (Figure 4)

- Four Risk maps showing minimum criticality routes for 50-, 100- and 475year periods.

The thematic maps graphically highlight those road stretches having the highest risk index which need to be given a higher priority when planning seismic retrofitting works to the road network.

\subsection{Phase 5 - risk evaluation of towns}

Besides drawing up risk maps of the sections constituting the road network, it is also possible to associate risk values to the accessibility of each town in the area under investigation according to the origin and type of route considered.

The sum of the damage indexes associated to the single links making up the $\mathrm{O} / \mathrm{D}_{\mathrm{i}}$ route are combined to the destination $\mathrm{D}_{\mathrm{i}}$. Multiplying the value thus obtained by the direct exposure of the destination town, it is possible to obtain the risk value associated to emergency service access in case of earthquake.

It is possible to define three histogram-based thematic maps according to the return time period considered (50, 100 or 475 years), which graphically show the risk associated with the optimum routes to each of the five destinations in terms of length (Lmin), time (Tmin), damage (Dmin) and transitability (Tr).

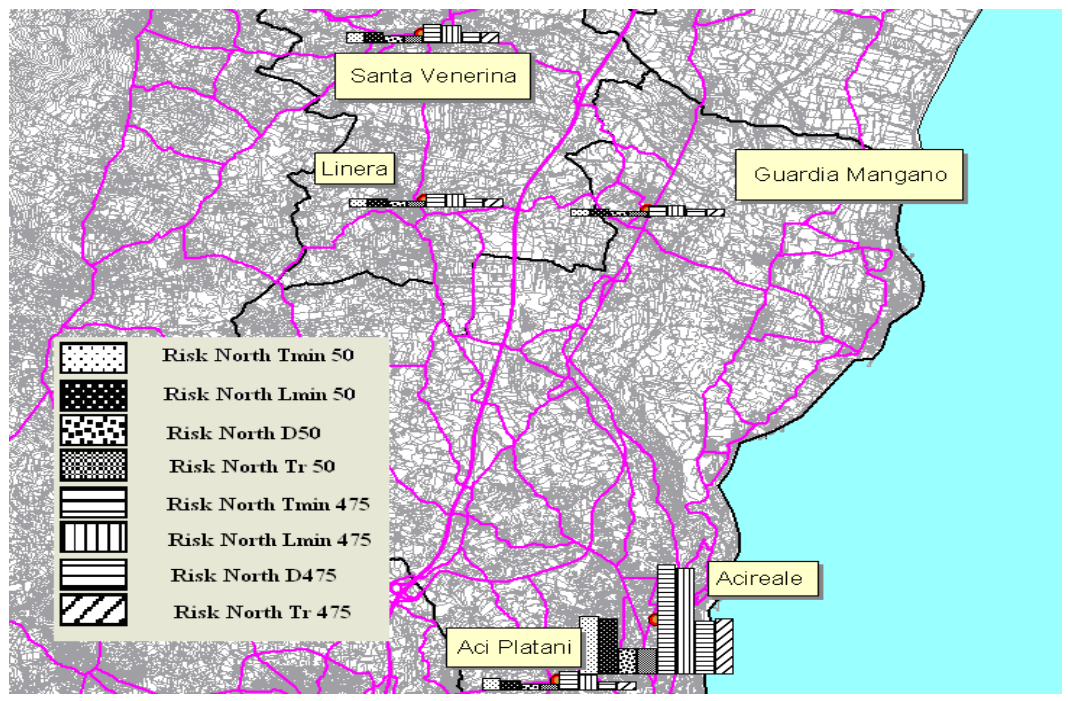

Figure 5: $\quad$ Seismic risk relating to emergency service access to affected towns (return time periods of 50 and 475 years, Origin North). 
From an analysis of the risk maps it can be seen that Acireale is the destination that, of all those considered, has the greatest risk value due to its higher direct exposure (33,010 inhabitants, seismic risk index 0.123).

From the histograms in Figure 5 it can be seen how, of all the routes analysed, the minimum time and minimum length routes are those with the highest risk value because these routes do not minimize the damage present along the route. It should be noted that these routes are those that the emergency services would tend to give priority to, if not adequately informed of any interruptions. In all cases, it can be seen how the risk values on the minimum length and minimum time routes with return periods of 50 and 100 years are very similar; while the risk values referring to a return time period of 475 years are almost double those of the 50 and 100 year-period values.

Instead, as regards the risk related to damage and to transitability calculated by minimizing the damage factor along the route, it is evident that there is a net reduction in the risk value as compared to that associated to the minimum length and minimum time routes.

Even if these routes ensure easier access to those towns affected by the quake, the journey time and distance can be considerably higher than those of the minimum length and time routes. Therefore, to evaluate the more disadvantaged conditions, two indexes were defined for each route concerning respectively variations in length $\Delta \mathrm{L}$ and time $\Delta \mathrm{T}$, calculated using the following formulas:

$$
\begin{aligned}
& \Delta \mathrm{L}_{\mathrm{i}}=\left(\mathrm{L}_{\mathrm{i}}-\mathrm{L}_{\min }\right) / \mathrm{L}_{\min } \times 100 . \\
& \Delta \mathrm{T}_{\mathrm{i}}=\left(\mathrm{T}_{\mathrm{i}}-\mathrm{T}_{\min }\right) / \mathrm{T}_{\min } \times 100 .
\end{aligned}
$$

where for each O/D pair:

$\mathrm{L}_{\mathrm{i}}$ is the length of the route with minimum damage, transitability;

$\mathrm{T}_{\mathrm{i}}$ is the time taken to cover the route with minimum damage, transitability, length;

$\mathrm{L}_{\min }$ is the length of the route with the minimum length;

$\mathrm{T}_{\min }$ is the time taken to travel the route with the minimum time.

The variation in length and time is an important factor, in that it makes it possible to equate how far it is justifiable to choose a route that minimizes damage as compared to a route that minimizes length and time.

\section{Conclusions}

The maintenance of an efficient road network after an earthquake is indispensable if emergency services from outside the area are to reach the affected zones as easily and quickly as possible. Therefore, it is equally indispensable for the risk to roads to be evaluated beforehand, so as to program seismic retrofitting works to the most vulnerable structures which are strategic to the efficient functioning of the road network.

This research proposes an original method of risk analysis, which makes it possible to identify beforehand those parts of the network with a higher level of risk both as regards possible structural damage and the importance of the 
connection, bearing in mind the number of inhabitants that can be reached by the emergency services. The analyses were carried out considering bridges as the "weak" element of the road infrastructure in cases of seismic events, but the procedure could also be applied to different types of element (trenches, embankments, culverts, etc).

Using a high seismic-risk area of eastern Sicily as a case study, it was possible to verify the effectiveness of the proposed procedure. In particular, implementing the method using the GIS made it possible to draw up maps which identify the most critical stretches for different earthquake scenarios (return times of 50, 100, 475 years) and emergency service origins. Those towns presenting the greatest risk of difficult access for the emergency services are also identified.

This information is useful in order to identify those parts of the road network where more resources should be employed both to program retrofitting work on structures and for a more in-depth analysis, evaluating in detail the vulnerability of bridges.

\section{Acknowledgement}

The authors would like to acknowledge the Sicilian Civil Protection for supporting the data acquisition.

\section{References}

[1] Wakabayashi H., Idia Y., Upper and Lower bounds of terminal reliability of road networks: an efficient method with Boolean Algebra. Journal of Natural Disaster Science 14, pp. 29-44, 1992.

[2] Cafiso S., Condorelli A., Mussumeci G. Functional analysis of the urban road network in seismic emergencies. GIS application on Catania city. Seismic Prevention of Damage: A case study in a Mediterranean City, pp. 393-408. WIT Press, 2005. ISBN: 1-84564-004-7.

[3] Cafiso S., Condorelli A., Cutrona G., Mussumeci G. A Seismic Network Reliability Evaluation on GIS Environment - A Case Study on Catania Province. Risk Analysis IV, 2004, pp. 131-140 - WIT Press, - ISBN 185312-736-1.

[4] Cafiso S., Condorelli A., D’Andrea A. Methodological Considerations for the Evaluation of Seismic Risk on Road Network. Pure and Applied Geophysics, Vol. 162, n. 4, 2005. pp. 767-782.

[5] Buckle I.G., Kim S.H., A vulnerability assessment for highway bridge. ASCE. Lifeline Earthquake Engineering, 1995.

[6] Istituto Nazionale di Geofisica e Vulcanologia (I.N.G.V.). Mappa di pericolosità sismica del territorio nazionale PCM n. 3519, All. 1b. April 2006 in http://zonesismiche.mi.ingv.it/

[7] Ord. P.C.M. n. 2788 del 12/06/1998, Individuazione delle zone ad elevato rischio sismico del territorio nazionale, 1998. 